\title{
Norepinephrine and Dopamine as Learning Signals
}

\author{
Carolyn W. Harley \\ Psychology Department, Memorial University of Newfoundland \\ St. John's, Newfoundland Canadi A1B $3 X 9$
}

\section{SUMMARY}

The present review focuses on the hypothesis that norepinephrine (NE) and dopamine (DA) act as learning signals. Both $\mathrm{NE}$ and $\mathrm{DA}$ are broadly distributed in areas concerned with the representation of the world and with the conjunction of sensory inputs and motor outputs. Both are released at times of novelty and uncertainty, providing plausible signal events for updating representations and associations. These catecholamines activate intracellular machinery postulated to serve as a memoryformation cascade. Yet, despite the plausibility of an NE and DA role in vertebrate learning and memory, most evidence that they provide a learning signal is circumstantial. The major weakness of the data available is the lack of a specific description of how the neural circuit modulated by NE or DA participates in the learning being analyzed. Identifying a conditioned stimuli (CS) representation would facilitate the identification of a learning signal role for NE or DA. Describing how the CS representation comes to relate to learned behavior, either through sensory-sensory associations, in which the CS acquires the motivational significance of reward or punishment, thus driving appropriate behavior, or through direct sensory-motor associations is necessary to identify how NE

\footnotetext{
Reprint requests to: Carolyn W. Harley, Psychology Dept., Memorial University of Newfoundland, St. John's, Newfoundland, Canada A1B 3X9; e-mail: charley @mun.ca
}

(C) 2004 Freund \& Pettman, U.K. and DA participate in memory creation. As described here, evidence consistent with a direct learning signal role for NE and DA is seen in the changing of sensory circuits in odor preference learning (NE), defensive conditioning (NE), and auditory cortex remodeling in adult rats (DA). Evidence that NE and DA contribute to normal learning through unspecified mechanisms is extensive, but the details of that support role are lacking.

\section{INTRODUCTION}

The projections of locus coeruleus (LC) norepinephrine (NE) cells and of midbrain dopamine (DA) cells interact with large regions of the vertebrate forebrain. Neuronal activity in these cell groups in behaving animals suggests they are active when new environmental contingencies occur. Norepinephrine and DA also engage the cyclic adenosine monophosphate (cAMP) cascade and, ultimately, activate the cAMP response element binding protein (CREB), a promoter of new protein transcription that is proposed to be universally involved in long-term memory formation (Silva et al., 1998). The present review examines the hypothesis that NE and DA provide learning signals through the activation of their respective cAMPcoupled receptors, the $\beta$-adrenergic receptor for NE and the D1/D5 receptor for DA.

The LC-NE neurons project to all cortical forebrain regions, as well as to the cerebellum, spinal cord, and limbic and hypothalamic nuclei (Moore \& Bloom, 1979). Midbrain DA neurons project 
heavily to the frontal cortex, striatum, and limbic areas; other cortical areas also receive DA innervation (Moore \& Bloom, 1978).

The diffuse projecting pattern of NE axons was part of Kety's (1970) initial rationale for proposing, more than 30 years ago, that NE would serve as a signal to produce persistent facilitation of synaptic inputs when those inputs occurred in conjunction with significant consequences for the organism. Livingston's (1967) proposal of a widely projecting "Now Print" message was similar to Kety's NE learning signal.

To mediate the learning effects of unconditioned stimuli (UCS), UCS should activate NE and DA neurons such that the release of NE and DA would occur in the appropriate temporal sequence to strengthen associated inputs. Cellularrecording studies indicate that both $\mathrm{NE}$ and $\mathrm{DA}$ neurons show patterns of activation that are consistent with a role as learning signals. The neurons do not invariably respond to unconditioned rewards or punishments, however, but instead are affected by the degree of predictability of such signals.

Midbrain DA neurons fire to unpredicted rewards and are depressed by the absence of predicted rewards (Hollerman \& Schultz, 1998). This DA cellular firing pattern has been described as a 'teaching' signal because it occurs before reliable cue and reward associations have been made and disappears as such associations become established (Waelti et al., 2001). Dopamine cell firing then becomes associated to the conditioned stimuli (CS) signaling reward and ultimately becomes associated only to the earliest CS in the temporal chain of events leading to reward (Schultz, 1998). Thus, DA cellular activity signals the UCS when learning is initiated and remains available as a signal to link temporal contingencies leading to reward, but dissociates from the primary reward event. The DA cellular signal can plausibly initiate learning induced by a reward UCS. Dopamine neurons are also activated by novelty
(Ljungberg et al., 1992). Aversive events are not potent activators of DA neurons (Mirenowicz \& Schultz, 1996).

When rewarding UCS are presented and are unpredictable, LC-NE neurons also fire (Sara et al., 1994; Sara, 1998). When conditioning to such stimuli is established, the neurons no longer fire unless the reward contingency changes. For example, if a reward is omitted during extinction, then the neurons will fire again (Sara \& Segal, 1991; Sara et al., 1994) in contrast to DA neurons, which decrease their firing rate when a predicted reward is omitted (Hollerman \& Schultz, 1998). Possibly related to the activation of NE neurons by reward omission is the recent report that extinction of taste aversions, an active learning process, depends on $\beta$-adrenergic-receptor activation (Berman \& Dudai, 2001).

The NE neurons are activated by both appetitive and aversive UCS (Sara \& Segal, 1991), by novel sensory events (Vankov et al., 1995; Aston-Jones \& Bloom, 1981b), or by any change in environmental contingencies that might cause an animal to orient or notice (Aston-Jones \& Bloom, 1981b; Vankov et al., 1995). Such neurons are tonically active as a function of arousal (Aston-Jones \& Bloom, 1981a) but produce burst responses (Grant et al., 1988; Aston-Jones et al., 1994) to significant events, as do DA neurons. Thus, the NE cellular signal is well timed to mediate the updating of representations or the acquisition of adaptive responses to important environmental events, as first discussed by Kety (1970). Both anatomical and signaling characteristics of NE and DA neurons in the vertebrate brain are consistent with a role for these neurotransmitters as learning signals.

Heterosynaptic facilitation by NE or DA of informational (usually glutamate) connections could promote a change in the response to that information. The change might represent sensorysensory or sensory-motivational associations, such that a previously neutral input calls up a second, 
behaviorally potent, representation, or a sensorymotor change such that a sensory input directly elicits a motor response. Connection change, functional and structural, is the current vision of the underpinning of memory in all nervous systems.

\section{HETEROSYNAPTIC FACILITATION BY NOREPINEPHRINE AND DOPAMINE}

Norepinephrine produces long-term synaptic facilitation of glutamatergic perforant-path input to the dentate gyrus (Neuman \& Harley, 1983; Lacaille \& Harley, 1985; Harley \& Milway, 1986; Stanton \& Sarvey, 1985a, 1987), which requires the $\beta$-adrenergic receptor activation (Stanton \& Sarvey, 1985a; Lacaille \& Harley, 1985; Harley \& Milway, 1986) and is associated with the elevation of cAMP (Stanton \& Sarvey, 1985b). The activation exhibits priming effects such that spaced repeated subthreshold applications of a $\beta$-receptor agonist can produce long-term synaptic facilitation (Dahl \& $\mathrm{Li}, 1994)$.

Burst activation of the LC has recently been shown to produce long-term heterosynaptic facilitation at the perforant-path synapse, which depends on $\beta$-adrenergic receptor activation and on protein synthesis (Walling \& Harley, 2004). Unexpectedly, long-term synaptic facilitation occurs independently of short-term synaptic facilitation, but an early increase in cell excitability is observed. This result suggests that in the vertebrate brain, NE can selectively promote long-term memory, as proposed from behavioral observations of rodents (Kobayashi et al., 2000; Izquierdo et al., 1998) and humans (Quevedo et al., 2003).

Dopamine application produces enduring heterosynaptic facilitation of glutamatergic inputs to the Mauthner cell in fish (Kumar \& Faber, 1999) and of muscarinic inputs to sympathetic ganglia in rabbits (Libet, 1992). Both effects require activating the cAMP cascade. Dopamine D1/D5 receptor-agonist application initiates a slowly developing and enduring potentiation of glutamatergic synaptic input in CA1 (Huang \& Kandel, 1995)

\section{NOREPINEPRINE AND DOPAMINE AS LEARNING SIGNALS}

In the infant rat pup, learning to prefer odors associated with maternal care helps the pup maintain proximity to the mother. Stroking and licking the pup produces a prolonged activation of LC neurons (Kimura \& Nakamura, 1985; Nakamura et al., 1987) and the release of NE in the olfactory bulb (Rangel \& Leon, 1995). When stroking is preceded by exposure to a novel odor, the pups learn a preference for the novel odor (Sullivan \& Hall, 1988). Backward pairings do not produce conditioning (Sullivan \& Hall, 1988). A $\beta$-adrenergic receptor agonist in the olfactory bulb can act as the UCS (Sullivan et al., 2000), whereas a $\beta$-adrenergic receptor antagonist in the olfactory bulb prevents odor preference learning to stroking UCS (Sullivan et al., 1992). Thus, NE release and $\beta$-adrenergic receptor activation in the olfactory bulb are both necessary and sufficient for rat pup odor preference learning (Wilson \& Sullivan, 1994).

Experiments in our laboratory have shown that intracellular cAMP elevation is essential for inducing odor preference memory. Phosphorylation of CREB, which modulates DNA transcription, is also essential in rat pup odor preference learning (Yuan et al., 2003a). A similar role has been shown for CREB in odor aversion learning in Drosophila (Yin et al., 1994, 1995).

Metabolic increases (Sullivan \& Leon, 1986; Sullivan et al., 1990) and CREB phosphorylation changes (McLean et al., 1999) associated with odor learning are localized to the olfactory bulb region, where the odor stimulus is encoded by mitral cells. We have suggested that the mitral cell is the locus of learning changes (Yuan et al., 2003b). Thus, although the specific circuit remains 
to be characterized, changes in the motivational significance of the odor, mediated by the changed patterns of mitral cell activity, produce learned odor-preference behavior.

The neuronal circuitry for odor preference learning in the olfactory bulb remains intact in adult rats, but LC signaling is altered after the neonatal period, providing only brief responses to tactile stimuli that, when paired with odor, do not produce odor preference learning or olfactory bulb change (Moriceau \& Sullivan, in press). Nevertheless, the pharmacological activation of the LC designed to reinstate the firing response pattern of the neonate rat reinstates LC mediation of odor preference learning in older rat pups.

In adult sheep, the NE release pattern associated with giving birth mediates the learning of an odor preference in the ewe for its own lamb after parturition (Brennan \& Keverne, 1997). Lamb odor preference learning depends on the activation of the $\beta$-adrenergic cascade in the olfactory bulb. The data from sheep and older rat pups support the hypothesis that the magnitude and duration of NE release are critical for its role in inducing long-term learning. This view is consistent with the proposed requirement for higher synaptic NE levels to induce long-term as opposed to short-term spike potentiation to glutamate input in the dentate gyrus (Harley et al., 1996).

Such LC activation also transmits the learning effects of a UCS in classically conditioned heart rate in the pigeon (Wall et al., 1985; Wild \& Cohen, 1985; Gibbs et al., 1986; Elmslie \& Cohen, 1990). A defensive response is conditioned by pairing light and shock. The CS and UCS pathways, their sites of interaction, and the behavioral circuit mediating the learned response have been identified. The first modification of sensory responses by conditioning occurring along the CS pathway is in a subset of neurons in the lateral geniculate nucleus. The LC mediates shockinduced cellular changes in the lateral geniculate nucleus neurons, which are seen subsequently in response to the light CS (Elmslie \& Cohen, 1990). As the input and the output pathways for lightevoked heart rate conditioning in pigeon are known, and the LC appears to provide the learning signal in this paradigm, further experiments with the pigeon model might further illuminate NE's role as a learning signal.

Vibrissae activation paired with shock produces a conditioned arousal to later vibrissae stimulation in the rat pup. This somatosensory conditioned response, which is not acquired in the presence of a $\beta$-adrenergic receptor antagonist, is mimicked by pairing vibrissae activation with a $\beta$-adrenergic receptor agonist (Landers \& Sullivan, 1999). In these appetitive and aversive paradigms, NE release acts as a signal to initiate changes that support learning and memory. The changes do not depend on the continued presence of NE for their expression (e.g., Sullivan \& Wilson, 1991).

Dopamine release is associated with natural reward, brain stimulation reward, and drugs of abuse (Wise, 2002). The activation of the DA system, as discussed by Wise, "somehow" serves to establish response habits. Yet, direct evidence for DA as a learning signal in classical conditioning is sparse. Dopamine reward signals in rodents energize and promote approach behaviors and enhance cue salience (Robinson \& Berridge, 2000). Although rats readily self-administer drugs that increase DA signals, the animals do not continue to bar-press in the absence of the signal, suggesting that DA is continuously needed to maintain or to motivate such behavior (e.g, Ranaldi \& Wise, 2001).

Reviewers concerned with drug addiction have argued that although DA motivational effects are important, cue or context learning dependent on D1 receptor activation in the striatum is likely to contribute to enduring changes in the response to drug-associated cues and environments (e.g., Berke \& Hyman, 2000). Nevertheless, the striatal experiments reviewed here show that whereas a DA psychostimulant like amphetamine can, when 
injected into the striatum, enhance the learning of a conditioned response to a visual or to an olfactory CS (Viaud \& White, 1989), amphetamine injections into the striatum cannot act as a UCS (Vezina \& Stewart, 1990).

The stimulation of midbrain DA neurons, when paired with an auditory tone, produces an enlarged cortical representation of the paired tone in auditory area 1 and a novel representation of the paired tone in auditory area 2, together with a diminution in response to the adjacent unpaired tone frequencies (Bao et al., 2001). This finding suggests that DA can mediate associative changes in cortical responses. Forward and backward pairings of midbrain DA stimulation and tone were tested. Only forward pairings-auditory stimulus followed by DA cell stimulation-produce altered cortical representations (Bao et al., 2001), which would be consistent with DA as a learning signal. The localization of the interaction between tone input and DA release has not been identified, nor is it known if the D1 receptor is critically involved.

Footshock paired with odor increases the odor synaptic input to basolateral amygdala neurons in the anesthetized rat. This associative change, which is localized to the neurons of the basolateral nucleus, requires DA (Grace \& Rosenkranz, 2002; Rosenkranz \& Grace, 2002). W hether a DA increase could substitute for the effects of the shock UCS or if shock is independently required to depolarize the postsynaptic cell is unclear. The requirement for D1-receptor activation was not tested.

\section{FORWARD VERSUS BACKWARD CONDITIONING}

For rat pup odor preference learning induced by $\beta$-adrenergic receptor activation and for cortical remodeling following pairing of auditory tone and midbrain DA activation, the importance of forward pairing of the neutral stimulus and UCS has been demonstrated. This phenomenon is a primary feature of classical conditioning. For organisms to learn 'what' leads to 'what', rather than nonspecifically associating events in any order, is critical. Learning signals using the cAMP cascade offer a mechanism for explaining the greater effectiveness of forward rather than backward pairings of CS and UCS.

In Aplysia, several groups have demonstrated that a CS allowing calcium entry primes adenylate cyclase such that higher levels of cAMP are achieved when the UCS arrives (Clark et al., 1994; Abrams et al., 1998; Yovell \& Abrams, 1992). Such facilitation of cAMP levels occurs only with the forward pairing of CS and UCS. Higher levels of cAMP in Aplysia are associated with a longer duration of synaptic plasticity (Bernier et al., 1982; Schacher et al., 1993; Schacher et al., 1988; Sun \& Schacher, 1996). In our rat pup model, we found that odor paired with UCS induces cAMP patterns that are not induced by UCS alone. In the vertebrate, patterns of cAMP rather than levels of cAMP might be the key to temporal-order effects in learning.

Homosynaptic glutamate N-methyl-D-aspartate (NMDA) mechanisms do not have a forward pairing requirement. Activation of the NMDA receptor requires a UCS-induced postsynaptic depolarization either before or concurrent with the arrival of the putative CS (Brown et al., 1988).

\section{PROLONGED NOREPINEPHRINE AND DOPAMINE ELEVATION}

The firing of NE and DA cells is temporally associated with environmental change and unpredicted reinforcers, but is transient. The pattern of cell firing suggests that only transient elevations of these catecholamines in terminal structures would occur except under special conditions, such as after a stroking UCS in rat pups when cell-firing is prolonged. If, however, microdialysis studies are 
used to evaluate the levels of NE and DA structures during learning, then a different picture emerges. A study by McIntyre et al. (2002) illustrates this difference. The findings demonstrate that NE in the amygdala is elevated for hours after a brief footshock is given in a novel environment, whereas $\mathrm{NE}$ in the amygdala dissipates relatively rapidly (over minutes) when a similar footshock is given in a familiar environment. In both instances, after the novel or familiar environment pairing with shock, NE levels are measured in a common home-cage environment. As recording studies have not documented an LC firing that outlasts footshock, the concomitant novel input regulates the duration of NE release to footshock in the amygdala.

This pattern of results suggests that other inputs might control the catecholamine release at terminal sites. The NE and DA terminals, for example, are regulated by glutamate-receptor activation, and enhanced release occurs in the presence of NMDA and non-NMDA agonists (Malva et al., 1994; Krebs et al., 1991; Wang et al., 1992). Prolonged elevation of NE when learning occurs, e.g., pairing of a novel environment with shock, suggests that heightened activation in glutamate circuits coding for the novel environment might sustain NE release. Learning is unlikely to occur with a familiar stimulus associated with a lesser level of sensory activation, even when paired with shock and in this instance stimulus-associated glutamate release would presumably be insufficient to sustain NE release. Sustained NE levels can be critical for NE's role as a learning signal. Consistent with this hypothesis, McIntyre et al. (2002) also showed that the level of prolonged NE increase in the amygdala associated with aversive conditioning predicts the strength of learning measured 24 hours later in a conditioned avoidance task.

Prolonged increases in the catecholamines could also account for the ability of postacquisition infusions of $\beta$-adrenergic or of D1/D5 antagonists to disrupt learning and memory (see review by Izquierdo et al., 2004, this issue.) Such memory-impairing effects argue that prolonged activation of the cAMP-coupled receptors is needed to produce stable learning. The learningsignal events that trigger acquisition might be inseparable from those associated with consolidation. Other studies (Sara et al., 1999) suggesting that the requirement for receptor activation can be markedly delayed argue for a separate catecholamine-associated consolidation event. Dopamine release in specific brain areas is also seen with aversive stimuli (e.g., Wilkinson et al., 1998), in contrast to weaker evidence for DA cell responses to aversive stimuli (but see Schultz \& Romo, 1987). Dopamine elevation with aversive events would be important if DA is to act as a learning signal in, for example, the odor followed by shock model described in the basolateral amygdala.

A caveat with respect to the foregoing discussion is that microdialysis measurements might not be sensitive to the learning signal events of primary interest. A recent study argues that microdialysis results for DA reflect different patterns of firing in the midbrain DA cell population (Floresco et al., 2003). A general increase in DA levels is associated with an overall increase in the number of DA cells firing. Burst responses associated with signaling do not initiate measurable DA increases because the release is synaptically targeted and reuptake mechanisms effectively remove synaptic DA. Burst responses, however, produce higher levels of local DA release than do increases in the DA cell population firing.

\section{REWARD AND PUNISHMENT}

Norepinephrine can mediate learning signals for both reward - as in odor preference learning in the rat pup-and for punishment-as suggested by the light-shock conditioning paradigm in the pigeon. Dopamine, although traditionally associated with 
reward, has also been shown to contribute to aversive learning (e.g., Guarraci et al., 1999) and as noted above, is elevated in aversive learning. Might these catecholamines act as affectively neutral learning signals such that their role is to bind associations but not to determine the 'quality' of those associations?

In the honeybee, the cAMP cascade is involved in both appetitive and aversive odor learning. The nature of the UCS neurotransmitters, octopamine or dopamine, determines the appetitive or aversive nature of the learning signal (Schwaerzel et al., 2003). The cAMP cascade mediates the UCS learning signal in both kinds of learning, but each transmitter is thought to recruit a different output pathway. In the vertebrate brain, cAMP cascades have also been implicated in appetitive (e.g., odor preference conditioning) and aversive (e.g., fear conditioning) learning. Thus, NE and DA could participate as UCS mediators for both types of learning if other factors like the structures mediating the representations or the outputs were distinct.

\section{NOREPINEPHRINE AND DOPAMINE AS LEARNING MODULATORS}

Rather than mediating the UCS learning signal, NE and DA might interact synergistically with learning signals mediated by other mechanisms. A homosynaptic glutamate NMDA mechanism and a heterosynaptic monoamine mechanism are both required for the full expression of conditioning in the invertebrate Aplysia (Antonov et al., 2003; Glanzman, 1995). In Aplysia, monoamine facilitation is presynaptic, whereas NMDA mechanisms are postsynaptic, although their co-activation leads to an increase in synaptic strength at the same loci. In vertebrates, an interaction of the two mechanisms in postsynaptic cells is common. Most likely, in the odor preference model discussed earlier, a novel odor signal normally produces a calcium influx through NMDA channels, and the calcium signal interacts with cAMP signals to restrict memory changes to the cell groups representing the odor. The NMDA channels are activated normally as part of the odor input in the rat pup. In other models, postsynaptic depolarization would be necessary for their participation.

Homosynaptic glutamate mechanisms have been well characterized in the vertebrate brain. Such mechanisms alone could support associative learning and could interact with cAMP cascade mechanisms as well. Two kinds of interaction might be envisioned.

- $\quad \mathrm{NE}$ and DA are required at basal or permissive levels to support the normal function of glutamate pathways.

- $\quad \mathrm{NE}$ and DA are required as synergistic learning signals to generate long-term memory in conjunction with homosynaptic glutamate mediated plasticity.

The permissive requirement is exemplified in the role of 5-hydroxytryptamine (5-HT) $5-\mathrm{HT}_{\mathrm{a} / \mathrm{c}}$ receptor subtypes in rat-pup odor learning, in which a 5- $\mathrm{HT}_{2 \mathrm{a} / \mathrm{c}}$ receptor antagonist (McLean et al., 1996) or 5-HT depletion (McLean et al., 1993) prevents learning but at the level of mechanism, $5-\mathrm{HT}_{2 \mathrm{a} / \mathrm{c}}$ receptors are acting to support the normal $\beta$-adrenergic receptor promotion of cAMP. On its own, 5-HT $2 \mathrm{a} / \mathrm{c}$-receptor activation cannot produce associative change, although its absence prevents learning (Price et al., 1998). Higher levels of $\beta$-adrenergic receptor activation overcome the requirement for 5-HT and reinstate odor preference learning (Langdon et al., 1997), confirming the UCS role of NE in this paradigm.

If $\mathrm{NE}$ and $\mathrm{DA}$ are required for normal cell excitability and normal intracellular signaling to glutamate inputs, then a blockade of $\beta$-adrenergic or D1/D5 receptors could impair learning without $\mathrm{NE}$ or DA acting as learning signals. Alternatively, as mentioned earlier, NE and DA could be, 
together with homosynaptic glutamate mechanisms, synergistic learning signals. The effects of receptor blockade might be indistinguishable in the two conditions, but the effects of increases in NE and DA receptor activation could be distinct, with additional NE and DA release promoting learning or homosynaptic glutamate-induced synaptic change.

A specific role for the cAMP cascade in the conversion of short-term memory to long-term memory has been proposed (Bailey et al., 1996). The primary tests of this hypothesis in vertebrates use tetanic stimulation to activate a short-duration, homosynaptic glutamate-synaptic potentiation. If manipulations like agonists of $\beta$-adrenergic or D1/D5 receptors are added to increase the activation of the cAMP cascade, then the hypothesis predicts the conversion from shorter-duration (early long-term potentiation or LTP) to longerduration potentiation (late LTP). Experiments of this type provide the most direct evidence that NE and DA act as synergistic learning signals with homosynaptic glutamate mechanisms.

\section{HOMOSYNAPTIC LONG-TERM POTENTIATION AND NOREPINEPHRINE AND DOPAMINE}

Reward or punishment recruits a change from weak to enduring LTP in the dentate gyrus. Such change does not occur in the presence of a $\beta$-adrenergic receptor antagonist. Because NE-cell activity is associated with reward or punishment, the antagonist result is consistent with NE acting as a synergistic learning signal to facilitate homosynaptic potentiation (Seidenbecher et al., 1997).

An exploration of novel environments transforms early LTP in the dentate gyrus into late LTP, requiring the activation of $\beta$-adrenergic receptors (Straube et al., 2003) Novel environments also recruit a change from weak to enduring LTP in area CA1 of the hippocampus, where blockade of DA (both D2 and D1/D5) receptors prevents the effect ( $\mathrm{Li}$ et al., 2003) and as reviewed earlier, novelty triggers both NE and DA cell activity.

The exogenous application of cAMP-coupled $\mathrm{NE}$ and DA agonists induces a switch from shortterm to long-term homosynaptic plasticity at the glutamate synapses. Applying a $\beta$-adrenergic agonist lowers the threshold for LTP in CA3 (Hopkins \& Johnston, 1988), whereas D1/D5 agonists switch early-phase to late-phase LTP in the frontal cortex (Gurden et al., 2000), the hippocampus (Kusuki et al., 1997; Swanson-Park et al., 1999), and enhance early-phase LTP magnitude in the hippocampus as well (Otmakhova \& Lisman, 1996). These effects differ from the direct heterosynaptic effects described earlier, which did not require the tetanization of glutamate pathways.

\section{OTHER ASPECTS OF MODULATOR FUNCTION}

Norepinephrine and dopamine cAMP-coupled receptor activation could promote homosynaptic glutamate mechanism in direct ways, as well as interacting through second messenger cascade synergy. The activation of D1/D5 receptors in the frontal cortex (Lavin \& Grace, 2001; Dong \& White, 2003), striatum (West \& Grace, 2002) (Kitai \& Surmeier, 1993), and hippocampus (Pedarzani \& Storm, 1995) can induce increased cell excitability. The NE activation of $\beta$ adrenergic receptors also increases cell excitability (Lacaille \& Schwartzkroin, 1988; Foehring et al., 1989; Stanton, 1992; Pedarzani \& Storm, 1996). Both DA and NE have been reported to reduce feed-forward inhibition concomitant with DA (Bissiere et al., 2003) or NE (Brown, 2003) pathway activation. Norepinephrine can also transiently suppress the higher beta and gamma frequency EEG oscillations that are associated with binding stable representations while promoting plasticity by enhancing theta rhythms (Brown, 2003). Dopamine suppresses higher frequency oscillations in certain models (Weiss et 
al., 2003). Finally, both NE (Stanton et al., 1989) and DA (Flores-Hernandez et al., 2002) facilitate NMDA currents. Together, these actions would directly promote glutamate-associated plasticity and new learning. The release of either catecholamine, however, engages a much more complex suite of actions than those enumerated here, with the involvement of multiple receptor types. The net effect would be dependent on the cells and on the circuits that were influenced.

\section{THE INVERTED U-CURVE}

One feature of NE and DA in the mediation of learning and memory is an inverted U-curve relation with the neurotransmitter level. This relation is illustrated in odor-preference memory in the rat pup.

- If a low dose of a $\beta$-adrenergic agonist is paired with odor, then no learning occurs.

- If a medium dose is paired with odor, then learning is successful.

- If a high dose is paired with odor, then learning fails (Sullivan et al., 1989).

Depleting 5-HT makes medium doses ineffective and high doses necessary, shifting the inverted U-curve to the right (Langdon et al., 1997). A weak stroking input summates with a low dose to produce an effective learning stimulus, but the same stroking input pushes a medium dose into the ineffective range (Sullivan et al., 1991). Thus signaling 'windows' exist for initiating memory. Similar signaling windows have been described for $\mathrm{DA}$ and NE in prefrontal working-memory models (Arnsten, 1997), but working memory requires a transient representation rather than the sustained connection changes considered here. That the bases for the inverted U-curves in these two types of memory are similar is unlikely.

A recent study suggests that excessive cAMP levels, created by removing an inhibitory constraint on adenylcyclase, enhance homosynaptic LTP in the hippocampus but impair normal spatial learning and memory (Pineda et al., 2004). The authors suggest that the system becomes too plastic to be functionally useful. Whether a similar explanation will account for other inverted U-curve relations of cAMP to memory remains to be discovered. In the odor preference learning model, greater $\beta$-adrenergic receptor activation does not produce enhanced odor-nerve excitatory post-synaptic potentials (EPSPs) or learning (Yuan et al., 2000).

In the dunce mutation in Drosophila, a decrement in the breakdown of cAMP through the loss of a phosphodiesterase gene prevents normal avoidance-learning to odor-shock pairing. Although an elevation in cAMP is critical for acquiring avoidance responses to odor-shock pairing in Drosophila, excessive elevation appears deleterious (Davis, 1996). Thus, when this cascade is part of the learning signal, inverted U-curve relations between CAMP and learning and memory appear to occur in both invertebrate and vertebrate nervous systems. Optimal requirements for cAMP signaling in memory remain to be defined.

\section{REFERENCES}

Abrams TW, Yovell Y, Onyike CU, Cohen JE, Jarrard HE. 1998. Analysis of sequencedependent interactions between transient calcium and transmitter stimuli in activating adenylyl cyclase in Aplysia: possible contribution to CSUS sequence requirement during conditioning. Learn Mem 4: 496-509.

Antonov I, Antonova I, Kandel ER, Hawkins RD. 2003. Activity-dependent presynaptic facilitation and hebbian LTP are both required and interact during classical conditioning in Aplysia. Neuron 37: 135-147.

Arnsten AF. 1997. Catecholamine regulation of the prefrontal cortex. J Psychopharmacol 11: 151162.

Aston-Jones G, Bloom FE. 1981a. Activity of norepinephrine-containing locus coeruleus neurons in behaving rats anticipates fluctuations in the sleepwaking cycle. J Neurosci 1: 876-886. 
Aston-Jones G, Bloom FE. 1981b. Norepinephrinecontaining locus coeruleus neurons in behaving rats exhibit pronounced responses to non-noxious environmental stimuli. J Neurosci 1: 887-900.

Aston-Jones G, Rajkowski J, Kubiak P, Alexinsky T. 1994. Locus coeruleus neurons in monkey are selectively activated by attended cues in a vigilance task. J Neurosci 14: 4467-4480.

Bailey CH, Bartsch D, Kandel ER. 1996. Toward a molecular definition of long-term memory storage. Proc Natl Acad Sci USA 93: 1344513452.

Bao S, Chan VT, Merzenich MM. 2001. Cortical remodelling induced by activity of ventral tegmental dopamine neurons. Nature 412: 79-83.

Berke JD, Hyman SE. 2000. Addiction, dopamine, and the molecular mechanisms of memory. Neuron 25: 515-532.

Berman DE, Dudai Y. 2001. Memory extinction, learning anew, and learning the new: dissociations in the molecular machinery of learning in cortex. Science 291: 2417-2419.

Bernier L, Castellucci VF, Kandel ER, Schwartz JH. 1982. Facilitatory transmitter causes a selective and prolonged increase in adenosine $3^{\prime}: 5^{\prime}$-monophosphate in sensory neurons mediating the gill and siphon withdrawal reflex in Aplysia. J Neurosci 2: 1682-1691.

Bissiere S, Humeau Y, Luthi A. 2003. Dopamine gates LTP induction in lateral amygdala by suppressing feedforward inhibition. Nat Neurosci 6: 587-592.

Brennan PA, Keverne EB. 1997. Neural mechanisms of mammalian olfactory learning. Prog Neurobiol 51: 457-481.

Brown RA. 2003. Trifling matters: Differential regulation of feedforward and feedback interneurons of the dentate gyrus by synaptically released norepinephrine. Memorial University of Newfoundland. Thesis/Dissertation

Brown TH, Chapman PF, Kairiss EW, Keenan CL. 1988. Long-term synaptic potentiation. Science 242: 724-728.

Clark GA, Hawkins RD, Kandel ER. 1994. Activitydependent enhancement of presynaptic facilitation provides a cellular mechanism for the temporal specificity of classical conditioning in Aplysia. Learn Mem 1: 243-257.

Dahl D, Li J. 1994. Induction of long-lasting potentiation by sequenced applications of isopro- terenol. Neuroreport 5: 657-660.

Davis RL. 1996. Physiology and biochemistry of Drosophila learning mutants. Physiol Rev 76: 299-317.

Dong Y, White FJ. 2003. Dopamine D1-class receptors selectively modulate a slowly inactivating potassium current in rat medial prefrontal cortex pyramidal neurons. J Neurosci 23: 26862695.

Elmslie KS, Cohen DH. 1990. Iontophoresis of norepinephrine onto neurons of the pigeon's lateral geniculate nucleus: characterization of an inhibitory response. Brain Res 517: 134-142.

Flores-Hernandez J, Cepeda C, HernandezEcheagaray E, Calvert CR, Jokel ES, Fienberg AA, et al. 2002. Dopamine enhancement of NMDA currents in dissociated medium-sized striatal neurons: role of $D 1$ receptors and DARPP-32. J Neurophysiol 88: 3010-3020.

Floresco SB, West AR, Ash B, Moore H, Grace AA. 2003. Afferent modulation of dopamine neuron firing differentially regulates tonic and phasic dopamine transmission. Nat Neurosci 6: 968-973.

Foehring RC, Schwindt PC, Crill WE. 1989. Norepinephrine selectively reduces slow $\mathrm{Ca} 2+-$ and $\mathrm{Na}+$-mediated $\mathrm{K}+$ currents in cat neocortical neurons. J Neurophysiol 61: 245-256.

Gibbs CM, Cohen DH, Broyles JL. 1986. Modification of the discharge of lateral geniculate neurons during visual learning. J Neurosci 6: 627-636.

Glanzman DL. 1995. The cellular basis of classical conditioning in Aplysia californica-it's less simple than you think. Trends Neurosci 18: 3036.

Grace AA, Rosenkranz JA. 2002. Regulation of conditioned responses of basolateral amygdala neurons. Physiol Behav 77: 489-493.

Grant SJ, Aston-Jones G, Redmond DE Jr. 1988. Responses of primate locus coeruleus neurons to simple and complex sensory stimuli. Brain Res Bull 21: 401-410.

Guarraci FA, Frohardt RJ, Kapp BS. 1999. Amygdaloid D1 dopamine receptor involvement in Pavlovian fear conditioning. Brain Res 827 : 28-40.

Gurden H, Takita M, Jay TM. 2000. Essential role of D1 but not D2 receptors in the NMDA receptordependent long-term potentiation at hippocampalprefrontal cortex synapses in vivo. J Neurosci 20 : RC106. 
Harley CW, Lalies MD, Nutt DJ. 1996. Estimating the synaptic concentration of norepinephrine in dentate gyrus which produces beta-receptor mediated long-lasting potentiation in vivo using microdialysis and intracerebroventricular norepinephrine. Brain Res 710: 293-298.

Harley CW, Milway JS. 1986. Glutamate ejection in the locus coeruleus enhances the perforant pathevoked population spike in the dentate gyrus. Exp Brain Res 63: 143-150.

Hollerman JR, Schultz W. 1998. Dopamine neurons report an error in the temporal prediction of reward during learning. Nat Neurosci 1: 304-309.

Hopkins WF, Johnston D. 1988. Noradrenergic enhancement of long-term potentiation at mossy fiber synapses in the hippocampus. $J$ Neurophysiol 59: 667-687.

Huang YY, Kandel ER. 1995. D1/D5 receptor agonists induce a protein synthesis-dependent late potentia-tion in the CA1 region of the hippocampus. Proc Natl Acad Sci USA 92: 24462450.

Izquierdo I, Medina $\mathrm{JH}$, Izquierdo LA, Barros DM, de Souza MM, Mello e Souza T. 1998. Short- and long-term memory are differentially regulated by monoaminergic systems in the rat brain. Neurobiol Learn Mem 69: 219-224.

Izquierdo I, Cammarota M, Medina JH, Bevilaqua LRM. 2004. Pharmacological findings on the biochemical bases of memory processes: a general view. Neural Plast 13: 159-189.

Kety S. 1970. The biogenic amines in the ce ntral nervous system: their possible roles in arousal, emotion and learning. In: Schmitt FO, ed, The Neurosciences: Second Study Program. New York, NY, USA: Rockefeller Press; 324-335.

Kimura F, Nakamura S. 1985. Locus coeruleus neurons in the neonatal rat: electrical activity and responses to sensory stimulation. Brain Res 355 : 301-305.

Kitai ST, Surmeier DJ. 1993. Cholinergic and dopaminergic modulation of potassium conductances in neostriatal neurons. Adv Neurol 60: 40-52.

Kobayashi K, Noda Y, Matsushita N, Nishii K, Sawada H, Nagatsu T, et al. 2000. Modest neuropsychological deficits caused by reduced noradrenaline metabolism in mice heterozygous for a mutated tyrosine hydroxylase gene. J Neurosci 20: 2418-2426.

Krebs MO, Desce JM, Kemel ML, Gauchy C,
Godeheu G, Cheramy A, et al. 1991. Glutamatergic control of dopamine release in the rat striatum: evidence for presynaptic $\mathrm{N}$-methylD-aspartate receptors on dopaminergic nerve terminals. J Neurochem 56: 81-85.

Kumar SS, Faber DS. 1999. Plasticity of first-order sensory synapses: interactions between homosynaptic long-term potentiation and heterosynaptically evoked dopaminergic potentiation. J Neurosci 19: 1620-1635.

Kusuki T, Imahori Y, Ueda S, Inokuchi K. 1997. Dopaminergic modulation of LTP induction in the dentate gyrus of intact brain. Neuroreport 8: 2037-2040.

Lacaille JC, Harley CW. 1985. The action of norepinephrine in the dentate gyrus: beta-mediated facilitation of evoked potentials in vitro. Brain Res 358: 210-220.

Lacaille JC, Schwartzkroin PA. 1988. Intracellular responses of rat hippocampal granule cells in vitro to discrete applications of norepinephrine. Neurosci Lett 89: 176-181.

Landers MS, Sullivan RM. 1999. Norepinephrine and associative conditioning in the neonatal rat somatosensory system. Brain Res Dev Brain Res 114: 261-264.

Langdon PE, Harley CW, McLean JH. 1997. Increased beta adrenoceptor activation overcomes conditioned olfactory learning deficits induced by serotonin depletion. Brain Res Dev Brain Res 102: 291-293.

Lavin A, Grace AA. 2001. Stimulation of D1-type dopamine receptors enhances excitability in prefrontal cortical pyramidal neurons in a statedependent manner. Neuroscience 104: 335-346.

Li S, Cullen WK, Anwyl R, Rowan MJ. 2003. Dopamine-dependent facilitation of LTP induction in hippocampal CA1 by exposure to spatial novelty. Nat Neurosci 6: 526-531.

Libet B. 1992. Introduction to slow synaptic potentials and their neuromodulation by dopamine. Can J Physiol Pharmacol 70 Suppl: S3-11.

Livingston RB. 1967. Brain circuitry relating to complex behavior. In: Quarton, GC, Melnechuk, T, Schmitt, FO, eds, The Neurosciences: A Study Program. New York, NY, USA: The Rockefeller Press; 499-515.

Ljungberg T, Apicella P, Schultz W. 1992. Responses of monkey dopamine neurons during 
learning of behavioral reactions. J Neurophysiol 67: 145-163.

Malva JO, Carvalho AP, Carvalho CM. 1994. Modulation of dopamine and noradrenaline release and of intracellular $\mathrm{Ca} 2+$ concentration by presynaptic glutamate receptors in hippocampus. $\mathrm{Br} J$ Pharmacol 113: 1439-1447.

McIntyre CK, Hatfield T, McGaugh JL. 2002. Amygdala norepinephrine levels after training predict inhibitory avoidance retention performance in rats. Eur J Neurosci 16: 1223-1226.

McLean JH, Darby-King A, Hodge E. 1996. 5-HT2 receptor involvement in conditioned olfactory learning in the neonate rat pup. Behav Neurosci 110: 1426-1434.

McLean JH, Darby-King A, Sullivan RM, King SR 1993. Serotonergic influence on olfactory learning in the neonate rat. Behav Neural Biol 60: 152-162:

McLean JH, Harley CW, Darby-King A, Yuan Q. 1999. pCREB in the neonate rat olfactory bulb is selectively and transiently increased by odor preference-conditioned training. Learn Mem 6: 608-618.

Mirenowicz J, Schultz W. 1996. Preferential activation of midbrain dopamine neurons by appetitive rather than aversive stimuli. Nature 379: 449-451.

Moore RY, Bloom FE. 1978. Central catecholamine neuron systems: anatomy and physiology of the dopamine systems. Annu Rev Neurosci 1: 129-169.

Moore RY, Bloom FE. 1979. Central catecholamine neuron systems: anatomy and physiology of the norepinephrine and epinephrine systems. Annu Rev Neurosci 2: 113-168.

Moriceau S, Sullivan RM. 2004. Unique neural circuitry for neonatal olfactory learning. J Neurosci 24: 1182-1189.

Nakamura S, Kimura F, Sakaguchi T. 1987. Postnatal development of electrical activity in the locus ceruleus. J Neurophysiol 58: 510-524.

Neuman RS, Harley CW. 1983. Long-lasting potentiation of the dentate gyrus population spike by norepinephrine. Brain Res 273: 162-165.

Otmakhova NA, Lisman JE. 1996. D1/D5 dopamine receptor activation increases the magnitude of early long-term potentiation at CA1 hippocampal synapses. J Neu rosci 16: 7478-7486.

Pedarzani P, Storm JF. 1995. Dopamine modulates the slow $\mathrm{Ca}(2+)$-activated $\mathrm{K}+$ current IAHP via cyclic AMP-dependent protein kinase in hippocampal neurons. J Neurophysiol 74: 2749-2753.
Pedarzani P, Storm JF. 1996. Interaction between alpha- and beta-adrenergic receptor agonists modulating the slow $\mathrm{Ca}(2+)$-activated $\mathrm{K}+$ current IAHP in hippocampal neurons. Eur J Neurosci 8: 2098-2110.

Pineda VV, Athos JI, Wang H, Celver J, Ippolito D, Boulay G, et al. 2004. Removal of G(ialphal) constraints on adenylyl cyclase in the hippocampus enhances LTP and impairs memory formation. Neuron 41: 153-163.

Price TL, Darby-King A, Harley CW, McLean JH. 1998. Serotonin plays a permissive role in conditioned olfactory learning induced by norepinephrine in the neonate rat. Behav Neurosci 112: 1430-1437.

Quevedo J, Sant' Anna MK, Madruga M, Lovato I, de Paris F, Kapczinski F, et al. 2003. Differential effects of emotional arousal in short- and longterm memory in healthy adults. Neurobiol Learn Mem 79: 132-135.

Ranaldi R, Wise RA. 2001. Blockade of D1 dopamine receptors in the ventral tegmental area decreases cocaine reward: possible role for dendritically released dopamine. J Neurosci 21 : 5841-5846.

Rangel S, Leon M. 1995. Early odor preference training increases olfactory bulb norepinephrine. Brain Res Dev Brain Res 85: 187-191.

Robinson TE, Berridge KC. 2000. The psychology and neurobiology of addiction: an incentivesensitization view. Addiction 95 Suppl 2: S91-117.

Rosenkranz JA, Grace AA. 2002. Dopaminemediated modulation of odour-evoked amygdala potentials during pavlovian conditioning. Nature 417: 282-287.

Sara SJ. 1998. Learning by neurones: role of attention, reinforcement and behaviour. C R Acad Sci III 321: 193-198.

Sara SJ, Roullet P, Przybyslawski J. 1999. Consolidation of memory for odor-reward association: betaadrenergic receptor involvement in the late phase. Learn Mem 6: 88-96.

Sara SJ, Segal M. 1991. Plasticity of sensory responses of locus coeruleus neurons in the behaving rat: implications for cognition. Prog Brain Res 88: 571-585.

Sara SJ, Vankov A, Herve A. 1994. Locus coeruleusevoked responses in behaving rats: a clue to the role of noradrenaline in memory. Brain Res Bull 35: 457-465. 
Schacher S, Castellucci VF, Kandel ER. 1988. cAMP evokes long-term facilitation in Aplysia sensory neurons that requires new protein synthesis. Science 240: 1667-1669.

Schacher S, Kandel ER, Montarolo P. 1993. cAMP and arachidonic acid simulate long-term structural and functional changes produced by neurotransmitters in Aplysia sensory neurons. Neuron 10: 1079-1088.

Schultz W. 1998. Predictive reward signal of dopamine neurons. J Neurophysiol 80: 1-27.

Schultz W, Romo R. 1987. Responses of nigrostriatal dopamine neurons to high-intensity somatosensory stimulation in the anesthetized monkey. J Neurophysiol 57: 201-217.

Schwaerzel M, Monastirioti M, Scholz H, FriggiGrelin F, Birman S, Heisenberg M. 2003. Dopamine and octopamine differentiate between aversive and appetitive olfactory memories in Drosophila. J Neurosci 23: 10495-10502.

Seidenbecher T, Reymann KG, Balschun D. 1997. A post-tetanic time window for the reinforcement of long-term potentiation by appetitive and aversive stimuli. Proc Natl Acad Sci USA 94: 1494-1499.

Silva AJ, Kogan JH, Frankland PW, Kida S. 1998. CREB and memory. Annu Rev Neurosci 21: 127148.

Stanton PK. 1992. Noradrenergic modulation of epileptiform bursting and synaptic plasticity in the dentate gyrus. Epilepsy Res Suppl 7: 135-150.

Stanton PK, Mody I, Heinemann U. 1989. A role for $\mathrm{N}$-methyl-D-aspartate receptors in norepinephrine-induced long-lasting potentiation in the dentate gyrus. Exp Brain Res 77: 517-530.

Stanton PK, Sarvey JM. 1985a. Blockade of norepinephrine-induced long-lasting potentiation in the hippocampal dentate gyrus by an inhibitor of protein synthesis. Brain Res 361: 276-283.

Stanton PK, Sarvey JM. 1985b. The effect of highfrequency electrical stimulation and norepinephrine on cyclic AMP levels in normal versus norepi-nephrine-depleted rat hippocampal slices. Brain Res 358: 343-348.

Stanton PK, Sarvey JM 1987. Norepinephrine regulates long-term potentiation of both the population spike and dendritic EPSP in hippo-campal dentate gyrus. Brain Res Bull 18: 115-119.

Straube T, Korz V, Balschun D, Frey JU. 2003. Requirement of beta-adrenergic receptor activation and protein synthesis for LTP-reinforcement by novelty in rat dentate gyrus. J Physiol 552: 953960.

Sullivan RM, Hall WG. 1988. Reinforcers in infancy: classical conditioning using stroking or intra-oral infusions of milk as UCS. Dev Psychobiol 21: 215-223.

Sullivan RM, Leon M. 1986. Early olfactory learning induces an enhanced olfactory bulb response in young rats. Brain Res 392: 278-282.

Sullivan RM, McGaugh JL, Leon M. 1991. Norepinephrine-induced plasticity and one-trial olfactory learning in neonatal rats. Brain Res Dev Brain Res 60: 219-228.

Sullivan RM, Stackenwalt G, Nasr F, Lemon C, Wilson DA. 2000. Association of an odor with activation of olfactory bulb noradrenergic betareceptors or locus coeruleus stimulation is sufficient to produce learned approach responses to that odor in neonatal rats. Behav Neurosci 114: 957-962.

Sullivan RM, Wilson DA. 1991. The role of norepinephrine in the expression of learned olfactory neurobehavioral responses in infant rats. Psycholobiology 19: 302-312.

Sullivan RM, Wilson DA, Leon M. 1989. Norepinephrine and learning-induced plasticity in infant rat olfactory system. J Neurosci 9: 3998-4006.

Sullivan RM, Wilson DA, Wong R, Correa A, Leon M. 1990. Modified behavioral and olfactory bulb responses to maternal odors in preweanling rats. Brain Res Dev Brain Res 53: 243-247.

Sullivan RM, Zyzak DR, Skierkowski P, Wilson DA. 1992. The role of olfactory bulb norepinephrine in early olfactory learning. Brain Res Dev Brain Res 70: 279-282.

Sun ZY, Schacher S 1996. Tetanic stimulation and cyclic adenosine monophosphate regulate segregation of presynaptic inputs on a common postsynaptic target neuron in vitro. J Neurobiol 29: 183-201.

Swanson-Park JL, Coussens CM, Mason-Parker SE, Raymond CR, Hargreaves EL, Dragunow M, et al. 1999. A double dissociation within the hippocampus of dopamine D1/D5 receptor and betaadrenergic receptor contributions to the persistence of long-term potentiation. Neuroscience 92: 485-497.

Vankov A, Herve-Minvielle A, Sara SJ. 1995. Response to novelty and its rapid habituation in locus coeruleus neurons of the freely exploring 
rat. Eur J Neurosci 7: 1180-1187.

Vezina P, Stewart J. 1990. Amphetamine administered to the ventral tegmental area but not to the nucleus accumbens sensitizes rats to systemic morphine: lack of conditioned effects. Brain Res 516: 99-106.

Viaud MD, White NM. 1989. Dissociation of visual and olfactory conditioning in the neostriatum of rats. Behav Brain Res 32: 31-42.

Waelti P, Dickinson A, Schultz W. 2001. Dopamine responses comply with basic assumptions of formal learning theory. Nature 412: 43-48.

Wall JT, Gibbs CM, Broyles JL, Cohen DH. 1985. Modification of neuronal discharge along the ascending tectofugal pathway during visual conditioning. Brain Res 342: 67-76.

Walling SG, Harley CW. 2004. Locus coeruleus activation initiates delayed synaptic potentiation of perforant path input to the dentate gyrus in awake rats: A novel b-adrenergic and protein synthesis dependent mammalian plasticity mechanism. J Neurosci 24: 598-604.

Wang JK, Andrews H, Thukral V. 1992. Presynaptic glutamate receptors regulate noradrenaline release from isolated nerve terminals. $J$ Neurochem 58: 204-211.

Weiss T, Veh RW, Heinemann U. 2003. Dopamine depresses cholinergic oscillatory network activity in rat hippocampus. Eur J Neurosci 18: 2573-2580.

West AR, Grace AA. 2002. Opposite influences of endogenous dopamine D1 and D2 receptor activation on activity states and electrophysiological properties of striatal neurons: studies combining in vivo intracellular recordings and reverse microdialysis. J Neurosci 22: 294-304.

Wild JM, Cohen DH. 1985. Invariance of retinal output during visual learning. Brain Res 331: 127-135.

Wilkinson LS, Humby T, Killcross AS, Torres EM, Everitt BJ, Robbins TW. 1998. Dissociations in dopamine release in medial prefrontal cortex and ventral striatum during the acquisition and extinction of classical aversive conditioning in the rat. Eur J Neurosci 10: 1019-1026.

Wilson DA, Sullivan RM. 1994. Neurobiology of associative learning in the neonate: early olfactory learning. Behav Neural Biol 61: 1-18.

Wise RA. 2002. Brain reward circuitry: insights from unsensed incentives. Neuron 36: 229-240.

Yin JC, Del Vecchio M, Zhou H, Tully T. 1995. CREB as a memory modulator: induced expression of a dCREB2 activator isoform enhances longterm memory in Drosophila. Cell 81: 107-115.

Yin JC, Wallach JS, Del Vecchio M, Wilder EL, Zhou H, Quinn WG, Tully T. 1994. Induction of a dominant negative CREB transgene specifically blocks long-term memory in Drosophila. Cell 79: 49-58.

Yovell Y, Abrams TW. 1992. Temporal asymmetry in activation of Aplysia adenylyl cyclase by calcium and transmitter may explain temporal requirements of conditioning. Proc Natl Acad Sci USA 89: 6526-6530.

Yuan Q, Harley CW, Bruce JC, Darby-King A, McLean JH. 2000. Isoproterenol increases CREB phosphorylation and olfactory nerve-evoked potentials in normal and 5-HT-depleted olfactory bulbs in rat pups only at doses that produce odor preference learning. Learn Mem 7: 413-421.

Yuan Q, Harley CW, Darby-King A, Neve RL, McLean JH. 2003a. Early odor preference learning in the rat: bidirectional effects of cAMP response element-binding protein (CREB. and mutant CREB support a causal role for phosphorylated CREB. J Neurosci 23: 4760-4765.

Yuan Q, Harley CW, McLean JH. 2003b. Mitral cell betal and 5-HT2A receptor colocalization and cAMP coregulation: a new model of norepinephrine-induced learning in the olfactory bulb. Learn Mem 10: 5-15. 

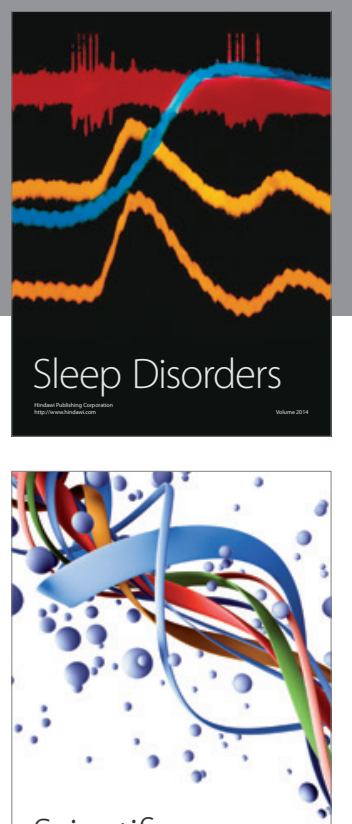

Scientifica
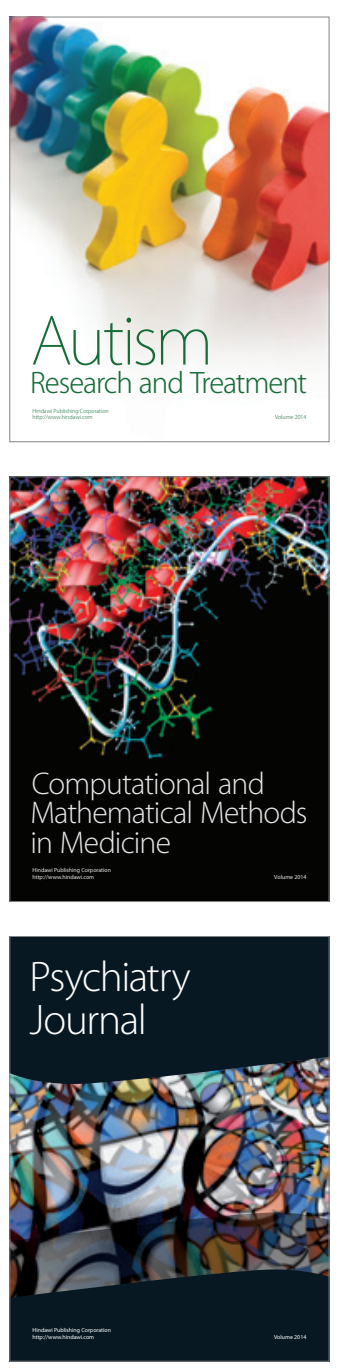
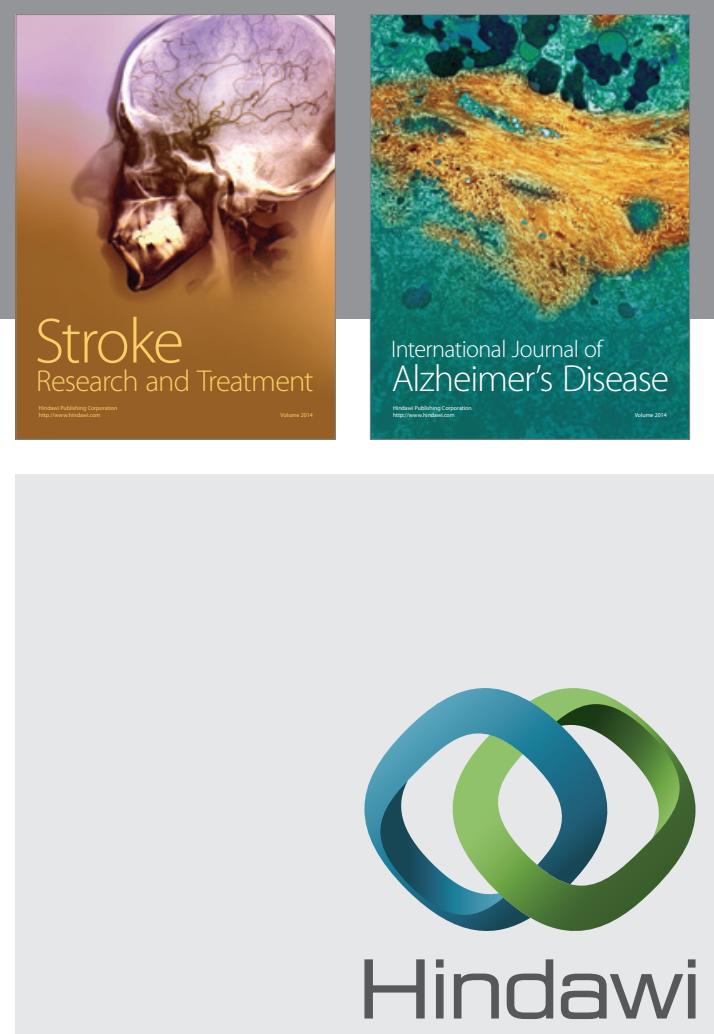

Submit your manuscripts at

http://www.hindawi.com
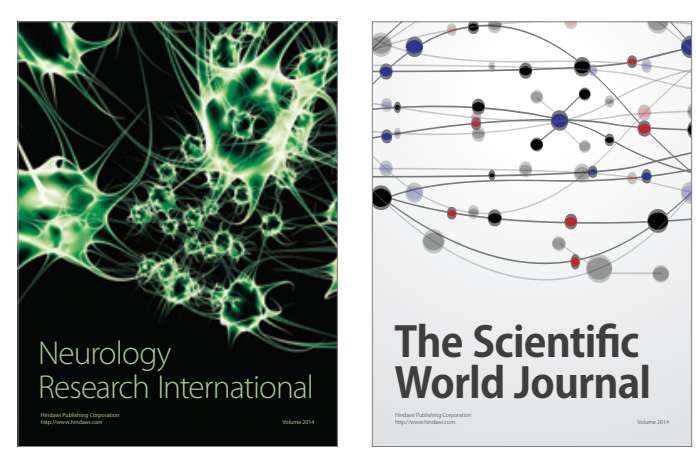

The Scientific World Journal

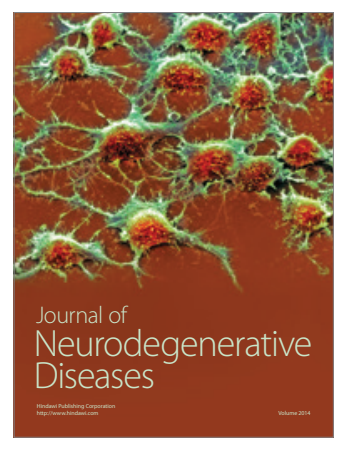

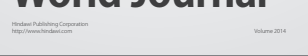

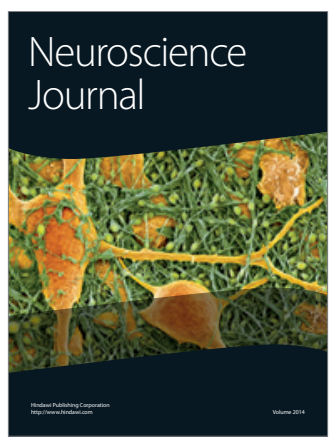

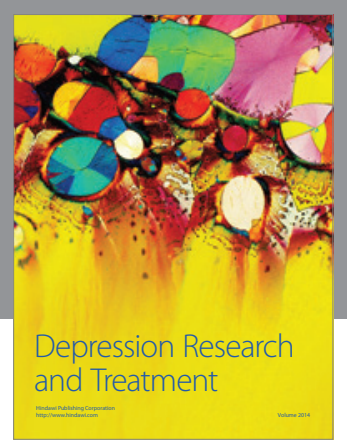
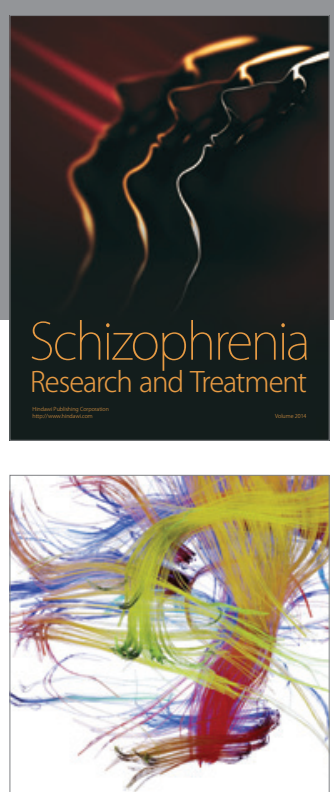

Brain Science

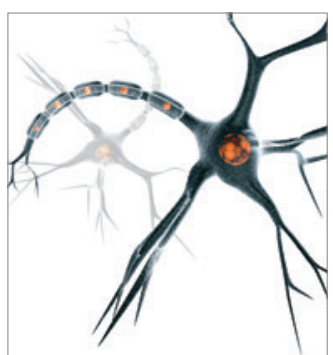

Neural Plasticity
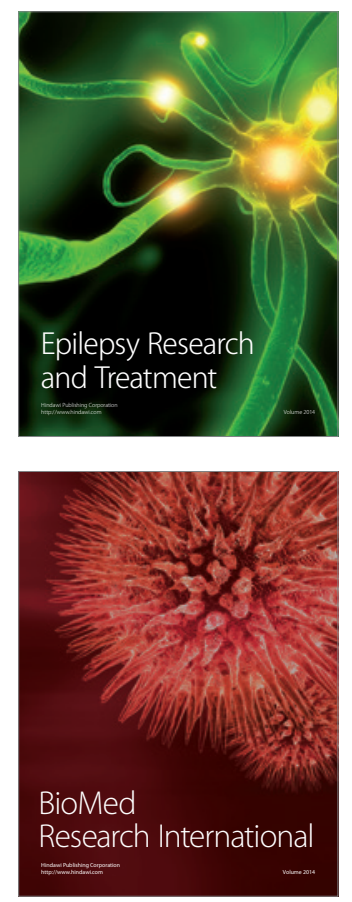

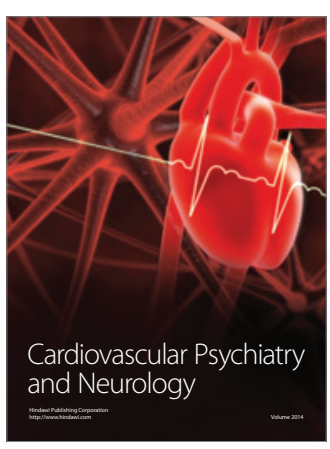

Parkinson's

Disease
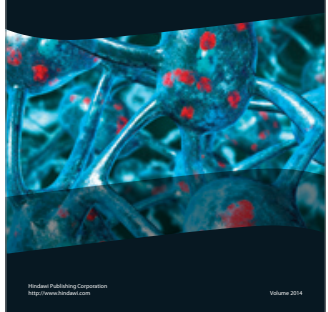